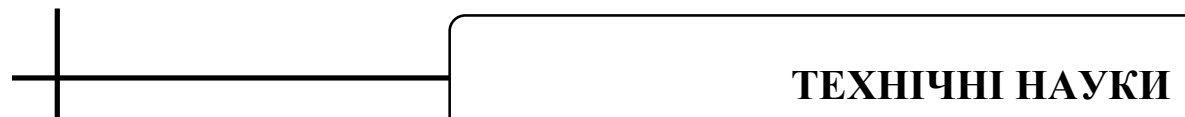

UDC: 621.373.826

DOI: $10.15587 / 2313-8416.2016 .58758$

\title{
PHOTONIC CRYSTAL FIBERS TECHNOLOGIES AND OPPORTUNITIES OF DEVELOPMENT IN TELECOMMUNICATIONS SYSTEMS
}

\author{
(C) Haider Ali Muse, T. Dribnokhod
}

Photonic crystal fibers compressors in fibre-laser systems allow the generation of output light pulses with a pulse width on the order of $100 \mathrm{fs}$ in the megawatt range of peak powers. Thus, Photonic crystal fibers play the key role in the development of novel fibre-laser sources of ultrashort light pulses and creation of fibre-format components for the control of such pulses. In this paper we will discuss the photonic crystal fibers technology development opportunities in the field of communications systems

Keywords: photonic crystal, communications, propagation, dispersion, photonic crystal fibers

\begin{abstract}
Фотонно-кристаллические волокна в волоконно-лазерных системах позволяют формировать выход световых импульсов с шириной импульса порядка 100 фс мегаватт в диапазоне пиковых мощностей. Таким образом, фотонно-кристаллические волокна играют главную роль в разработке новых волоконнолазерных источников сверхкоротких световых импульсов и создания компонентов волоконного формата для контроля таких импульсов. В этой статье мы обсудим возможности для развития фотоннокристаллических волокон в телекоммуникационной системе
\end{abstract}

Ключевые слова: фотонный кристалл, коммуникации, распространения, дисперсию, фотонный кристалл волокон

\section{Introduction}

In 1910 Hondros and Debye [1] conducted a theoretical study, and experimental work was reported by Schriever in 1920 [2]. Before 1970, optical fibers were used mainly for medical imaging over short distances [3]. Their use for communication purposes was considered impractical because of high losses $(1000 \mathrm{~dB} / \mathrm{km})$. However, the situation changed drastically in 1970 when, following an earlier suggestion, the loss of optical fibers was reduced to below $20 \mathrm{~dB} / \mathrm{km}$ [4]. Further progress resulted by 1979 in a loss of only $0.2 \mathrm{~dB} / \mathrm{km}$ near the $1.55-\mu \mathrm{m}$ spectral region [5]. The availability of low-loss fibers led to a revolution in the field of light wave technology and started the era of fiber-optic communications. Several books devoted entirely to optical fibers cover numerous advances made in their design and understanding [6]. In 1987, Yablonovitch and John - by using the tools of classical electromagnetism and solid-state physics - introduced the concepts of omnidirectional photonic band gaps in two and three dimensions [7]. From then, the name "photonic crystal" was created and led to many subsequent developments in their fabrication, theory, and application. A few years later in 1991, Yablonovitch and co-workers produced the first photonic crystal by mechanically drilling holes a millimeter in diameter into a block of material with a refractive index of 3.6 [8]. Other structures, which have band gaps at microwave and radio frequencies, are being used to make e. g. antennas that direct radiation away from the heads of mobile phone users. There are typically three types of computational methods: time-domain "numerical experiments" [9] that model the time-evolution of the fields with arbitrary starting conditions in a discredited system; definitefrequency transfer matrices wherein the scattering matrices are computed to extract transmission/reflection through the structure; and frequency-domain methods [10] to directly extract the Bloch fields and frequencies by diagonalizing the eigenoperator.

\section{Literature review}

The development of optical fibers over the last 20 years has resulted in the production of optical fiber cables which exhibit very low attenuation or transmission loss in comparison with the best copper conductors. Optical fibers which are fabricated from glass, or sometimes a plastic polymer, are electrical insulators and therefore, unlike their metallic counterparts, they do not exhibit earth loop and interface problems. Furthermore, this property makes optical fiber transmission ideally suited for communication in electrically hazardous environments as the fibers create no arcing or spark hazard at abrasions or short circuits. 


\section{The objective of the paper}

In communication the fibers could provide many new solutions. The photonic crystal fibers offer the possibility of low losses and dispersion, a possible competitor to conventional fibers. For photonic crystal fibers to realize their potential and advantages over conventional fibers in fiber optic communication. These fibers are based on a new and very promising technology and could provide solutions to many optical problems in communications, light source manufacturing and has already revolutionized the field of frequency metrology.

\section{Photonic crystal fibres}

Photonic crystals are periodic structures of dielectric materials and can today be produced with almost any imaginable structure. It is only a decade ago that BoseEinstein condensation was first achieved in alkali gases [11] and it has certainly turned into a very rich field since the condensates are very flexible model systems for solid state physics and statistical physics in general. Photoniccrystal fibres (PCFs) [12], also referred to as microstructure, or holey, fibres, are optical waveguides of a new type. In PCFs, radiation can be transmitted through hollow core (Fig. 1), surrounded with a microstructured cladding, consisting of an array of cylindrical air holes running along the fibre axis. Such a microstructure is usually fabricated by drawing a perform composed of capillary tubes and solid silica rods.

Along with conventional waveguide regimes, provided by total internal reflection, PCFs under certain conditions can support guided modes of electromagnetic radiation due to the high reflectivity of their cladding within photonic band-gaps (PBGs) or regions of low densities of photonic states [13], as well as by the antiresonance mechanism of waveguiding [14]. Such regimes can be supported by fibres with a hollow [15] core and a two-dimensionally periodic (photonic crystal) cladding. A high reflectivity provided by the PBGs in the transmission of such a cladding confines radiation in a hollow core, substantially reducing the loss, which is typical of hollow-core-guided modes in conventional, capillary-type hollow waveguides and which rapidly grows with a decrease in the diameter of the hollow core [16]. Unique properties of PCFs open up new routes for a long-distance transmission of electromagnetic radiation [12], as well as for nonlinear-optical transformation of laser pulses [17]. Photonic-crystal fibres offer new solutions for laser physics, nonlinear optics, and optical technologies, as they combine dispersion tuneability and a high degree of light-field confinement in the fibre core. The maximum laser fluence in an optical system is limited by the laser damage of material of optical components. An increase in a fibre cross section is a standard strategy for increasing the energy of laser pulses delivered by fibre lasers. Standard large-core-area fibres are, however, multimode, making it difficult to achieve a high quality of the transverse beam profile. This difficulty can be resolved by using PCFs with small-diameter air holes in the cladding, which filter out high-order waveguide modes [18].

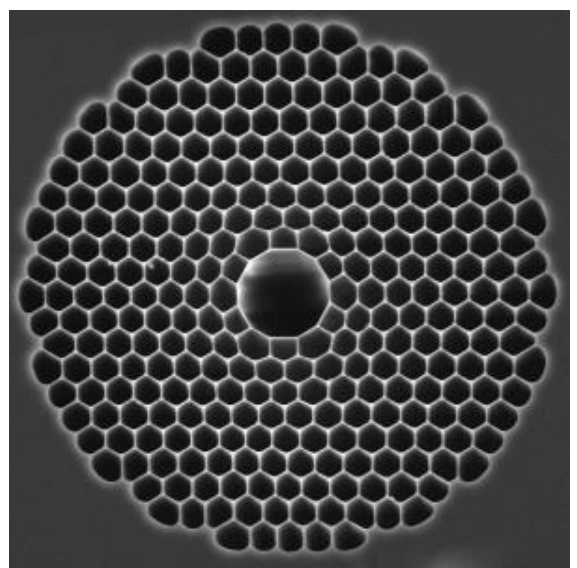

Fig. 1. Cross-section of photonic-crystal fibres

\section{The photonic crystal fibers and conventional optical fibers technology \\ There is a difference between the conventional optical fibers and photonic crystal fibres technology ,we can be captured by a set of more specific performance parameters as described below in Table 1 .}

Comparison of the performance parameters for photonic crystal fibres and conventional optical fibers

\begin{tabular}{|c|c|c|}
\hline Feature & Conventional fiber & Hollow core fiber \\
\hline Fiber diameter & $\begin{array}{c}\text { Typ. } 80 \mu \mathrm{m} \text { clad, } \\
170 \mu \mathrm{m} \text { coating }\end{array}$ & $\begin{array}{c}\text { Development fibers } 125 \mu \mathrm{m} \text { clad, } \\
240 \mu \mathrm{m} \text { clad }\end{array}$ \\
\hline Fiber bend diameter & Typ. $2-3 \mathrm{inch}$ & $<1 \mathrm{inch}$ \\
\hline Thermal stability & Shupe effect limits & $<15 \mathrm{~dB} / \mathrm{km}$ \\
\hline Loss (PM fiber) $1550 \mathrm{~nm}$ & $<3 \mathrm{~dB} / \mathrm{km}$ & $<2 \mathrm{~dB} / \mathrm{km}$ \\
\hline Loss (PM fiber) $1550 \mathrm{~nm}$ & $<3 \mathrm{~dB} / \mathrm{km}$ & Est. $>100 \mathrm{x}$ better \\
\hline Nonlinearities & Kerr effect limits & Better than stress part designs \\
\hline $\begin{array}{c}\text { Polarization maintenance thermal } \\
\text { stability }\end{array}$ & $\begin{array}{c}\text { Poor if using stress parts for } \\
\text { polarization maintenance }\end{array}$ & Est. 50x better \\
\hline Radiation sensitivity & Poor if using co-doped silica & Est. $>100 \mathrm{x}$ better \\
\hline Magnetic sensitivity & Faraday effect limits (less in a PM fiber) & \\
\hline
\end{tabular}

\section{Optical fiber communication system}

An optical fiber communication system is similar in basic concept to any type of communication system. A block schematic of a general communication system is shown in Fig. 2, the function of which is to convey the signal from the information over the transmission medium (photonic crystal fiber) to the destination. The communication system is consists of a transmission medium, 
and a receiver or demodulator at the destination point. The optical source which provides the electrical-optical conversion may be either a semiconductor IR. The transmission medium consists of photonic crystal fiber and the receiver consists of an optical detector (photodiode) which drives a further electrical stage and hence provides demodulation of the optical carrier. Photodiodes are utilized for the detection of the optical signal and the optical-electrical conversion. Thus there is a requirement for electrical interfacing at either end of the optical link and at present the signal processing is usually performed electrically.

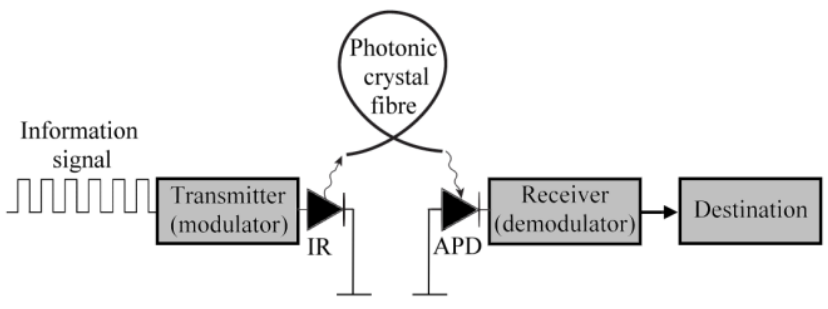

Fig. 2. General communication system

\section{The results and calculation of the propaga-}

tion

The spacing between the air holes in a photonic crystal structure with air holes embedded in dielectric material is given roughly by the wavelength of the light divided by the refractive index of the dielectric material. The problem in making these small structures is enhanced because it is more favorable for a photonic band gap to form in dielectrics with a high refractive index, which reduces the size of the lattice spacing even further. The linear part is

$$
\begin{gathered}
\frac{d^{2}}{d z^{2}} \tilde{G}(z, \omega)+\beta(\omega)^{2} \tilde{G}(z, \omega)=-\frac{\omega^{2}}{c^{2}} \frac{x^{(3)}}{A_{e f f}(\omega)} \tilde{p}(z, \omega), \\
\frac{d^{2}}{d z^{2}} \widehat{G}(z, \omega)=-\beta(\omega)^{2} \widehat{G}(z, \omega)
\end{gathered}
$$

Decoupling Maxwells equations with no free charges and currents, assuming linear response of the medium and no losses leads to a wave equation for the $H \omega(r)$ field

$$
\nabla \times\left[\frac{1}{\varepsilon(r)} \nabla \times H_{\omega}(r)\right]=\left(\frac{\omega}{c}\right)^{2} H_{\omega}(r),
$$

where $\varepsilon$ is the dielectric function.

$$
H_{\omega}(r)=\sum_{m} \alpha_{m} h_{m}(x, y) e^{-i \beta^{(m)}(\omega) z}
$$

where $m$ denotes the $m$ th eigenmode with transverse part $\boldsymbol{h} m(x, y)$ and propagation constant $\beta^{(m)}(\omega)$.

And Eq. (3) both originate from Maxwell's linear equations. By considering the magnetic field $\mathbf{H} \omega(\mathbf{r})$ as given by Eq. (4) and taking the second derivative with respect to $\mathrm{z}$ the following equation arises

$$
\frac{d^{2}}{d z^{2}} H_{\omega}(r)=-\beta(\omega)^{2} H_{\omega}(r) .
$$

The magnetic and electric fields are related by

$$
E_{\omega}(r)=-\frac{i c}{\omega \varepsilon(x, y)} \nabla \times H_{\omega}(r),
$$

where with translational symmetry $\varepsilon(x, y)$ is independent of z. Consequently, $\mathbf{E} \omega(\mathbf{r})$ also fulfills Eq. (2). The emitting power of the light (IR) from the transmitter may take many reflected and refracted paths before arriving at the receiver. The receiver in a optical communication system is the light detector (photodiode). The large size of the photodiode with respect to the wavelength of the light provides a degree of inherent spatial diversity in the receiver which mitigates the impact of multipath fading. Multipath fading is not a major impediment to optical communication, temporal dispersion of the received signal due to multipath propagation remains a problem. This dispersion is often modeled as a linear time invariant system since the channel properties change slowly over many symbol periods [19].

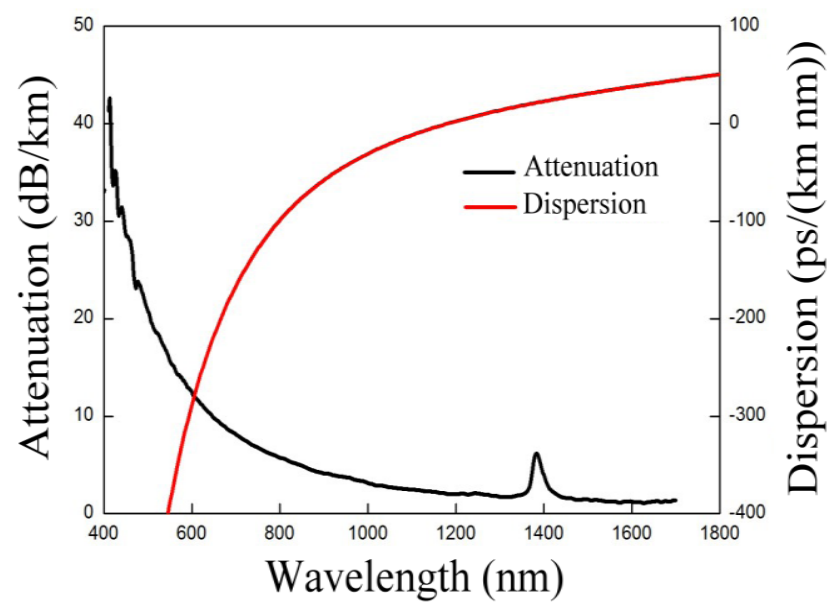

Fig. 3. Distribution and attenuation of the output power with a hollow core photonic crystal fibers

The impact of multipath dispersion is most noticeable in diffuse infrared communication systems. Unlike conventional fiber optical systems, multipath fading is not a major impairment in photonic crystal fiber transmission. The multipath propagation of light produces fades in the amplitude of the received electromagnetic signal at spacing on the order of half a wavelength apart. The fig. 3 illustrates the distribution and attenuation photonic crystal fibers with diameter $10 \mu \mathrm{m}$.

\section{Conclusion}

The transverse micro-structuring makes the dispersion of the fibers highly tunable and together with the high index contrast it leads to the small effective area, cade of nonlinear effects can take place in the fibers. The interplay between the special dispersion of the fibers and these nonlinear effects makes the phenomenon of supercontinuum generation possible. The full frequency de- 
pendency of the propagation constant as well as the effective transverse area serve as input for the model and these parameters can either be calculated as measured. Low loss per unit length, to satisfy the optical power budget allocation for fiber loss and low backscatter, to prevent noise and associated measurement error. The low nonlinearities, such as the Kerr effect, whereby refractive index dependencies in the light-guiding material due to electric field can cause a non-reciprocal effect in the fiber loop leading to measurement error.

\section{References}

1. Hondros, D. Electromagnetic waves along long cylinders of dielectric [Text] / D. Hondros, P. Debye // Ann. Phys. - 1910. - Vol. 32, Issue 3. - P. 465-476.

2. Schriever, O. Electromagnetic waves in dielectric wires [Text] / O. Schriever // Ann. Phys. - 1920. - Vol. 63, Issue 7. - P. 645-673.

3. Kapany, N. S. Fiber Optics. Principles and Applications [Text] / N. S. Kapany. - Academic Press, New York, 1967. $-447 \mathrm{p}$.

4. Kapron, F. P. RADIATION LOSSES IN GLASS OPTICAL WAVEGUIDES [Text] / F. P. Kapron // Applied Physics Letters. - 1970. - Vol. 17, Issue 10. - P. 423. doi: 10.1063/ 1.1653255

5. Miya, T. Ultimate low-loss single-mode fibre at $1.55 \mu \mathrm{m}[$ Text] / T. Miya, Y. Terunuma, T. Hosaka, T. Miyashita // Electronics Letters. - 1979. - Vol. 15, Issue 4. - P. 106. doi: 10.1049/el:19790077

6. Adams, M. J. An Introduction to Optical Waveguides [Text] / M. J. Adams. - John Wiley \& Sons, 1981. - 401 p.

7. Yablonovitch, E. Inhibited Spontaneous Emission in Solid-State Physics and Electronics [Text] / E. Yablonovitch // Physical Review Letters. - 1987. - Vol. 58, Issue20. - P. 20592062. doi: 10.1103/physrevlett.58.2059

8. Yablonovitch, E. Photonic Band Structure: The FaceCentered-Cubic Case Employing Nonspherical Atoms [Text] / E. Yablonovitch, T. J. Gmitter, K. M. Leung // Physical Review Letters. - 1991. - Vol. 67, Issue 17. - P. 2295-2298. doi: 10.1103/ physrevlett.67.2295

9. Chan, C. T. New structures and algorithms for photonic band gaps [Text] / C. T. Chan, S. Datta, Q. L. Yu, M. Sigalas, K. M. Ho, C. M. Soukoulis // Physica A: Statistical Mechanics and its Applications. - 1994. - Vol. 211, Issue 4. P. 411-419. doi: 10.1016/0378-4371(94)00133-2

10. Johnson, S. Block-iterative frequency-domain methods for Maxwell's equations in a planewave basis [Text] / S. Johnson, J. Joannopoulos // Optics Express. - 2001. - Vol. 8, Issue 3. - P. 173. doi: 10.1364/oe.8.000173

11. Anderson, M. Observation of Bose-Einstein Condensation in a Dilute Atomic Vapor [Text] / M. H. Anderson, J. R. Ensher, M. R. Matthews, C. E. Wieman, E. A. Cornell // Science. - 1995. - Vol. 269, Issue 5221. - P. 198-201. doi: 10.1126/ science.269.5221.198

12. Russell, P. Photonic Crystal Fibers [Text] / P. Russell // Science. - 2003. - Vol. 299, Issue 5605. - P. 358-362. doi: $10.1126 /$ science. 1079280

13. Knight, J. C. Photonic Band Gap Guidance in Optical Fibers [Text] / J. C. Knight, J. Broeng, T. A. Birks, P. S. J. Russell // Science. - 1998. - Vol. 282, Issue 5393. - P. 14761478. doi: 10.1126/science.282.5393.1476

14. Russell, P. S. J. Photonic-Crystal Fibers [Text] / P. S. J. Russell // Journal of Lightwave Technology. - 2006. Vol. 24, Issue 12. - P. 4729-4749. doi: 10.1109/jlt.2006. 885258

15. Cregan, R. F. Single-Mode Photonic Band Gap Guidance of Light in Air [Text] / R. F. Cregan, B. J. Mangan, J. C. Knight, T. A. Birks, P. S. J. Russell, P. J. Roberts,
D. C. Allan // Science. - 1999. - Vol. 285, Issue 5433. - P. 15371539. doi: $10.1126 /$ science. 285.5433 .1537

16. Marcatili, E. A. J. Hollow Metallic and Dielectric Waveguides for Long Distance Optical Transmission and Lasers [Text] / E. A. J. Marcatili, R. A. Schmeltzer // Bell System Technical Journal. - 1964. - Vol. 43, Issue 4. - P. 1783-1809. doi: 10.1002/j.1538-7305.1964.tb04108.x

17. Zheltikov, A. M. Nonlinear optics of microstructure fibers [Text] / A. M. Zheltikov // Physics-Uspekhi. - 2004. Vol. 47, Issue 1. - P. 69-98. doi: 10.1070/pu2004v047n01 abeh001731

18. Knight, J. C. All-silica single-mode optical fiber with photonic crystal cladding [Text] / J. C. Knight, T. A. Birks, P. S. J. Russell, D. M. Atkin // Optics Letters. - 1996. Vol. 21, Issue 19. - 1547. doi: 10.1364/ol.21.001547

19. Gfeller, F. R. Wireless in-house communication via diffuse infrared radiation [Text] / F. R. Gfeller, U. Bapst // Proceedings of the IEEE. - 1979. - Vol. 67, Issue 11. - P. 14741486. doi: 10.1109/proc. 1979.11508

\section{References}

1. Hondros, D., Debye, P. (1910). Electromagnetic waves along long cylinders of dielectric. Ann. Phys., 32 (3), 465-476.

2. Schriever, O. (1920). Electromagnetic waves in dielectric wires. Ann. Phys., 63 (7), 645-673.

3. Kapany, N. S. (1967). Fiber Optics. Principles and Applications. Academic Press, New York, 447.

4. Kapron, F. P. (1970). RADIATION LOSSES IN GLASS OPTICAL WAVEGUIDES. Applied Physics Letters, 17 (10), 423. doi: 10.1063/1.1653255

5. Miya, T., Terunuma, Y., Hosaka, T., Miyashita, T. (1979). Ultimate low-loss single-mode fibre at $1.55 \mu \mathrm{m}$. Electronics Letters, 15 (4), 106. doi: 10.1049/el:19790077

6. Adams, M. J. (1981). An Introduction to Optical Waveguides. John Wiley \& Sons, 401.

7. Yablonovitch, E. (1987). Inhibited Spontaneous Emission in Solid-State Physics and Electronics. Physical Review Letters, 58 (20), 2059-2062. doi: 10.1103/physrevlett. 58.2059

8. Yablonovitch, E., Gmitter, T., Leung, K. (1991). Photonic band structure: The face-centered-cubic case employing nonspherical atoms. Physical Review Letters, 67 (17), 2295-2298. doi: 10.1103/physrevlett.67.2295

9. Chan, C. T., Datta, S., Yu, Q. L., Sigalas, M., Ho, K. M., Soukoulis, C. M. (1994). New structures and algorithms for photonic band gaps. Physica A: Statistical Mechanics and Its Applications, 211 (4), 411-419. doi: 10.1016/0378-4371(94)00133-2

10. Johnson, S., Joannopoulos, J. (2001). Block-iterative frequency-domain methods for Maxwell's equations in a planewave basis. Optics Express, 8 (3), 173. doi: 10.1364/ oe.8.000173

11. Anderson, M. H., Ensher, J. R., Matthews, M. R., Wieman, C. E., Cornell, E. A. (1995). Observation of BoseEinstein Condensation in a Dilute Atomic Vapor. Science, 269 (5221), 198-201. doi: 10.1126/science.269.5221.198

12. Russell, P. (2003). Photonic Crystal Fibers. Science, 299 (5605), 358-362. doi: 10.1126/science.1079280

13. Knight, J. C., Broeng, J., Birks, T. A., Russell, P. S. J. (1998). Photonic Band Gap Guidance in Optical Fibers. Science, 282 (5393), 1476-1478. doi: 10.1126/science.282. 5393.1476

14. Russell, P. S. J. (2006). Photonic-Crystal Fibers. Journal of Lightwave Technology, 24 (12), 4729-4749. doi: 10.1109/ jlt.2006.885258

15. Cregan, R. F., Mangan, B. J., Knight, J. C., Birks, T. A., Russell, P. S. J., Roberts, P. J., Allan, D. C. (1999). SingleMode Photonic Band Gap Guidance of Light in Air. Science, 285 (5433), 1537-1539. doi: 10.1126/science.285.5433.1537 
16. Marcatili, E. A. J., Schmeltzer, R. A. (1964). Hollow Metallic and Dielectric Waveguides for Long Distance Optical Transmission and Lasers. Bell System Technical Journal, 43 (4), 1783-1809. doi: 10.1002/j.1538-7305.1964.tb04108.x

17. Zheltikov, A. M. (2004). Nonlinear optics of microstructure fibers. Physics-Uspekhi, 47 (1), 69-98. doi: 10.1070/ pu2004v047n01abeh001731
18. Knight, J. C., Birks, T. A., Russell, P. S. J., Atkin, D. M. (1996). All-silica single-mode optical fiber with photonic crystal cladding. Optics Letters, 21 (19), 1547. doi: 10.1364/ ol.21.001547

19. Gfeller, F. R., Bapst, U. (1979). Wireless in-house data communication via diffuse infrared radiation. Proceedings of the IEEE, 67 (11), 1474-1486. doi: 10.1109/proc.1979.11508

Рекомендовано до публікації д-р техн. наук Мачехін Ю. П. Дата надходження рукопису 17.12.2015

Haider Ali Muse, Postgraduate student, Department of Physical Foundations of Electronic Engineering, Kharkiv national university of radio electronics, Lenina ave., 14, Kharkiv, Ukraine, 61166

E-mail: Hadr_2005@yahoo.com

Tatyana Dribnokhod, Department of Physical Foundations of Electronic Engineering, Kharkiv national university of radio electronics, Lenina ave., 14, Kharkiv, Ukraine, 61166

E-mail: tatyana.dribnokhod@gmail.com

\title{
УДК 621.567
}

DOI: $10.15587 / 2313-8416.2016 .58770$

\section{РАЗМЕРНАЯ ТОЧНОСТЬ СПЕЧЕННЫХ ЗАГОТОВОК}

\author{
(C) Ч. А. Алиев
}

В статье приведены результаты оценки влияния стабильности поведения компонентов, входящих в состав композиций и технологических параметров их получения, на размерную точность заготовок. Установлено, что при увеличении количества оксида в составе композиции происходит большее уплотнение спеченной заготовки в проиессе термической обработки. При этом также происходит увеличение плотности всех составляющих композиции

Ключевые слова: размерная точность, спеченная заготовка, плотность, аналитическое выражение, оксид, вариация

The article presents the results of assessing the impact of the behaviour stability of the components included in the compositions and process parameters of their production, on the dimensional accuracy of workpieces. It was found that by increasing the amount of oxide in the composition is greater compaction of the sintered billet in the process of heat treatment. This also increases the density of all components of the composition

Keywords: dimensional accuracy, sintered billet, density, analytical expression, oxide, variation

\section{1. Введение}

Получение композиций типа «металлыоксиды-фенол-формальде-гидная смола (ФФС)» является приоритетным направлением на пути расширения номенклатуры заготовок сложной формы. Однако для изготовления композиций заготовок путем свободной заливки в форму смеси компонентов с последующим спеканием необходимо умело управлять изменением формы и размером конечных заготовок [1-3].

При выборе той или иной технологии изготовления заготовок вопросы размерной точности являются определяющими. В особенности это относятся к случаю получения заготовок сложной формы, так как обработка всех поверхностей таких заготовок сопоставима с их получением механообработкой из отливок, поковок, штамповок и т. д.

2. Постановка проблемы и анализ литературных данных

С точки зрения размерной точности, рассматриваемая в работе технология получения порошко- вых заготовок принципиально отличается от принятых. Эта разница состоит в том, что в традиционных технологиях в процессе мехобработки плотность заготовки остается практически неизменно и в то время как усадка составляет несколько процентов. В рассматриваемой технологии плотность материала заготовок может несколько раз изменяется тогда, как усадка может составлять 20-30\% от номинальной величины.

В то же время, используя материалы, обладающие высокими стабильными физическими и технологическими свойствами, а также высокоточные режимы обработки, можно достичь размерной точности, сопоставимой или превосходящей этот показатель у заготовок, изготавливаемых принятыми способами [4-6].

\section{3. Проведения теоретической оценки изго-} товления спеченных заготовок

С целью проведения теоретической оценки влияния стабильности параметров компонентов, входящих в состав композиций, и основных технологи- 